\title{
CLINICO-AETIOPATHOLOGICAL STUDY OF ERYTHRODERMA
}

\author{
Chetana $P^{1}$, Krishnakanth $M^{2}$, Sudha $R^{3}$, Gayathri $R^{4}$, Murugan $S^{5}$, Adikrishnan $S^{6}$, Mahalakshmi $V^{7}$
}

\begin{abstract}
${ }_{1}^{1}$ Junior Resident, Department of Dermatology, Sri Ramachandra Medical College and Research Institute, Chennai. ${ }^{2}$ Associate Professor, Department of Dermatology, Sri Ramachandra Medical Collegeand Research Institute, Chennai. ${ }^{3}$ Professor, Department of Dermatology, Sri Ramachandra Medical Collegeand Research Institute, Chennai. ${ }^{4}$ Senior Resident, Department of Dermatology, Sri Ramachandra Medical Collegeand Research Institute, Chennai. 5 Professor, Department of Dermatology, Sri Ramachandra Medical Collegeand Research Institute, Chennai. ${ }^{6}$ Associate Professor, Department of Dermatology, Sri Ramachandra Medical Collegeand Research Institute, Chennai. 7Professor, Department of Dermatology, Sri Ramachandra Medical Collegeand Research Institute, Chennai.
\end{abstract}

ABSTRACT: Erythroderma refers to any inflammatory skin disease affecting either sex or any age group resulting in erythema and exfoliation that affects more than $90 \%$ of the body surface. It may result from a pre-existing dermatoses or underlying lymphoma, drug eruption, hereditary causes eg: ichthyosiform erythroderma. Hence it is mandatory to establish the cause in order to facilitate its management.Since it is a complex disorder, the patient should preferably be hospitalized for evaluation and treatment. To study the clinical profile of patients with erythroderma and to identify the aetiological factors of erythroderma and its histopathological correlation and also it's associated systemic complication. A total number of 57 clinically diagnosed cases of erythroderma attended the department during the period from 2012 to 2014 and were taken up for the clinio-aetiopathological evaluation. Males outnumbered females with a ratio of 1.48:1. Predominant symptoms were erythroderma (96.49\%), exfoliation (100\%), itching (100\%). Nail change were seen in $75.43 \%$ of patients. The most common underlying etiology observed was psoriasis (43.85\%) followed by drug inducted erythroderma (36.84\%). The most common reaction pattern observed was psoriasiform pattern (59.6\%). In 16 $(33.33 \%)$ patients biopsy helped in reaching the diagnosis.Erythroderma can be fatal, even when properly managed, primarily because of its metabolic complications. Hence it is mandatory to establish its aetiopathology in order to facilitate more practiced management apart from the routine basic management.

KEYWORDS: Erythroderma.

HOW TO CITE THIS ARTICLE: Chetana P, Krishnakanth M, Sudha R, Gayathri R, Murugan S, Adikrishnan S, Mahalakshmi V. “ClinicoAetiopathological Study of Erythroderma". Journal of Evolution of Medical and Dental Sciences 2015; Vol. 4, Issue 88, November 02; Page: 15360-15366, DOI: $10.14260 /$ jemds/2015/2186.

INTRODUCTION: Erythroderma refers to any inflammatory skin disease affecting either sex or any age group resulting in erythema and exfoliation that affects more than $90 \%$ of the body surface. It may result from a pre-existing dermatoses or underlying lymphoma, drug eruptions, hereditary causes eg: ichthyosiform erythroderma. Hence it is mandatory to establish the cause in order to facilitate its management.

The potential complications include secondary infections. electrolyte imbalance, dehydration, temperature dysregulation, high output cardiac failure and death.

Since it is a complex disorder and is considered as one of the dermatologic emergency, the patient should preferably be hospitalized for evaluation and treatment.

MATERIALS AND METHODS:To study the clinical profile of patients with erythroderma and to identify the aetiological factors of erythroderma and its histopathological correlation and also its associated systemic complication. A total number of 57 clinically diagnosed cases of erythroderma attended the dermatology department during the period from 2012 to 2014 and were taken up for the clinio-aetiopathological

Financial or Other, Competing Interest: None.

Submission 10-10-2015, Peer Review 12-10-2015

Acceptance 20-10-2015, Published 02-11-2015.

Corresponding Author:

Dr. Krishnakanth $M$,

Door. No.123\#1, Vellala Street,

Purasawalkam, Chennai-84.

E-mail: krishnakanthmuralidhar@gmail.com

DOI: $10.14260 /$ jemds $/ 2015 / 2186$. evaluation. Patients of all ages and both the sexes who were willing to participate in the study were included.

It was an Observational, Descriptive \& Prospective hospitalbased study. The materials included recording of participant demographics, documentation of clinical history, past medical and surgical history. The baseline investigations-Complete blood count, Renal and Liver function test, serum electrolytes, Urine microscopy.

Chest X ray-PAview, Ultrasound-abdomen, ECG were done. Skin biopsy was done in 48 patients. Skin biopsy was not done in severely ill patients with altered coagulation profile. Statistical Analysis was done using the Statistical package for the Social Sciences (SPSS V 17.1). Quantitive variable are expressed as mean. +- standard Deviation. Qualitative variable are expressed as percentage values.

RESULTS AND ANALYSIS: The most common underlying etiology of erythroderma found in the study was psoriasis (43.85\%) followed by drug induced (36.84\%). Other etiologies which were noted include air borne contact dermatitis (7.01\%), pemphigus foliaceus (3.5\%), non-bullous ichthyosiform erythroderma (3.5\%) and atopic dermatitis (1.75\%). Etiology could not be identified in 2 patients (3.5\%)

DISCUSSION: A total number of 57 clinically diagnosed cases of erythroderma attended the our department during the period from December 2012 to September 2014 and were taken up for the clinio-aetiopathological evaluation.

In this study, male outnumbered female in the ratio of 1.48:1Earlier studies also demonstrated the same.[1],[2] 
Involvement of palms and soles were seen in $63.15 \%$ of patients in this study while it was observed in $39.13 \%$ cases in a study conducted by Bharatiya PR et al[ ${ }^{[3]}$ and in $30 \%$ of cases in a study done by pal Haroon. ${ }^{[4]}$ In this study, the mucosal involvement was recorded in $18(31.57 \%)$ cases.

However, in the study conducted by Pal S Haroon the mucosal involvement was observed in $36.6 \%$ of cases and $1 \%$ in a study conducted by Akhyani et al..[5]

In this study, psoriasis (43.85\%) was the commonest cause of erythroderma. Similar findings were observed in studies conducted by bharatiya et al.[3] Pal S Haroon. ${ }^{[4]}$ Wilson et al.[6]

Erythrodrema due to underlying pemphigus foliaceus was seen in $3.5 \%$ of patients in this study. In studies conducted by Abrahams et al.[7] King Le et al.[8] this dermatoses did not exceed 2\%. In a study conducted by Pal S and Haroon,4the frequency of pemphigus foliaceus was 5.6 whereas $6.25 \%$ in a study conducted by Rym et al.[9]

Erythroderma secondary to malignancy was not observed in this study. Similar findings were observed in a study conducted by Sehgal and Srivatsava [10], while Botella Estroda et al [11]. (Botella-Estrada R, Sanmartin O, Oliver V, Febrer I, Aliaga A. Erythroderma: A clinicopathological study of 56 cases. Arch Dermatol 1994;130:1503-7) reported $12.5 \%$ of erythroderma occurred due to cutaneous T-cell lymphoma and Kind Le et al ${ }^{[8]}$ observed that $20 \%$ cases occurred due to lymphoreticulat neoplasms, especially cutaneous T-cell lymphoma.

In this study, $8.77 \%$ cases of erythroderma occurred secondary to various eczematous conditions, such as Air borne contact dermatitis $(7.01 \%)$ and atopic dermatitis (1.75\%). Erythroderma secondary to eczema was seen in $20 \%$ of cases in a study conducted by Chaundary et al.[12]

In $3.5 \%$ of patients, the cause of erythroderma could not be found in this study. Similarly, in a study conducted by Rym et al.[10] the cause could not be determined in $7.5 \%$ of patients and in $18 \%$ patients in another study conducted by Javeria et al.[13] The cause could not be found in $14.6 \%$ of cases in a study done by Pal S and Haroon.

Among the 57 patients who were enrolled in this study, one patient $(1.75 \%)$ was HIV- positive. The cause of erythroderma was due to unknown drug intake. There was no HIV - infected patients in a study conducted by Akhyani et al.[5] In a study conducted by Morar et al, drug reactions $(40.6 \%)$ was the most common cause of erythroderma in HIVpositive patients and also concluded that in the young black patients erythroderma may be a marker for HIV infection.[14]

During the study period, death occurred in two (3.5\%) out of 57 patients due to fulminant hepatitis and cardiac failure. Similarly two patients died due to cardiac failure and septicaemia in a study conducted by sarkar et al.[15] In a study conducted by Rym et al, the proportion of death was 3.75\%. ${ }^{9}$ (Rym BM, Mourad M, Bechir Z Dalenda E, Faika C, Iadh AM, et al. Erythroderma in adults: A report of 80 cases. Int J Dermatol 2005;44:731-5).

CONCLUSION: Predominant symptoms were erythroderma (96.49\%), exfoliation (100\%), itching (100\%). Nail change were seen in $75.43 \%$ of patients. The most common underlying etiology observed was psoriasis (43.85\%) followed by drug inducted erythroderma (36.84\%). The most common reaction pattern observed was psoriasiform pattern (59.6\%).
In $16(33.33 \%)$ patients biopsy helped in reaching a diagnosis Erythroderma can be fatal, even when properly managed, primarily because of its metabolic complications. Hence it is mandatory to establish its aetiopathology in order to facilitate more practiced management apart from the routine basic management.

This study will help in educating patients with underlying disease (eg. Psoriasis, atopic dermatitis) about possible triggers of erythroderma (Irritants, abrupt discontinuation of certain therapies) in order to prevent the complication and to avoid medications \& irritants that have previously caused erythroderma and also to create awareness among the medical professionals regarding the medications that are potentially cross-reactive.

\section{REFERENCES:}

1. Hulmani M, NandaKishore B, Bhat M R, Sukumar D, Martis J, Kamath G, Srinath M K. Clinico-etiological study of 30 erythroderma cases from tertiary center in South India. Indian Dermatol Online J 2014;5:25-9.

2. Sudha R, Hussain S B, Bellraj E, Frederick M, Mahalaxmi V, Sobhana S, Anandan S. clinicopathological study of exfoliative dermatitis. Indian J Dermatol Venereol Leprol 2003;69:30-1

3. Bharatiya PR, Joshi PB. Study of exfoliative dermatitis. Indian J Dermatol Venereol Leprol 1995;61:81-3

4. Pal S, Haroon TS. Erythroderma: A clinic-etiologic study of 90 cases. Int J Dermatol 1998;37:104-7

5. Akhyani M, Ghodsi ZS, Toosi S, Dabbaghian H. Erythroderma: A clinical study of 97 cases. BMC Dermatol 2005;5:5.

6. Wilson HTH. Exfoliative dermatitis: its etiology and prognosis. Arch Dermatol. Syphilol. 1954,69:577-588.

7. Abrahams I, McCarthy JT, Sanders SL. 101 cases of exfoliative dermatitis. Arch Dermatol 1963;8:96-101.

8. King LE, Durfesne RG, Lovert G, et al. Erythroderma: review of 82 cases. South Med J 1986;79: 1210-1215.

9. Rym BM, Mourad M, Bechir Z Dalenda E, Faika C, Iadh AM, et al. Erythroderma in adults: A report of 80 cases. Int J Dermatol 2005;44:731-5.

10. Sehgal VN, Srivastava G. Exfoliative dermatitis: A prospective study of 80 patients. Dermatologica 1986;173:278-84.

11. Botella-Estrada R, Sanmartin O, Oliver V, Febrer I, Aliaga A. Erythroderma: A clinicopathological study of 56 cases. Arch Dermatol 1994;130:1503-7

12. Chaudhary A, Gupte PD. Erythroderma: a study of incidence and aetiopathologenesis. Indian J Dermatol Venereol Leprol 1997;63:38-9

13. Javeria Hafeez, Zafar Iqbal Shaikh, Asher Ahmad Mashhood, Simeen-Ber-Rahman. Frequency of various etiological factors associated with erythroderma. Journal of Pakistan Association of Dermatologist. 2010; 20:70-74

14. Morar N, Dlova N, Gupta AK, Naidoo DK, Aboobaker J, Ramdial PK. Erythroderma: A comparison between HIV positive and negative patients. Int J Dermatol 1999;38:895-900.

15. Sarkar R, Sharma RC, Koranne RV, Sardana K. Erythroderma: A clinico- etiology study. J Dermatol 1999;26:507-11. 


\begin{tabular}{|c|c|}
\hline ETIOLOGY & \% (n=57) \\
\hline Drug induced & 36.84 \\
\hline Psoriasis & 43.85 \\
\hline Pemphigus Foliaceus & 3.50 \\
\hline ABCD & 7.01 \\
\hline NBIE & 3.50 \\
\hline Atopic Dermatitis & 1.80 \\
\hline Unknown etiology & 3.50 \\
\hline \multicolumn{2}{|c|}{ Table 1.1: Showing the common Etiology } \\
\hline
\end{tabular}

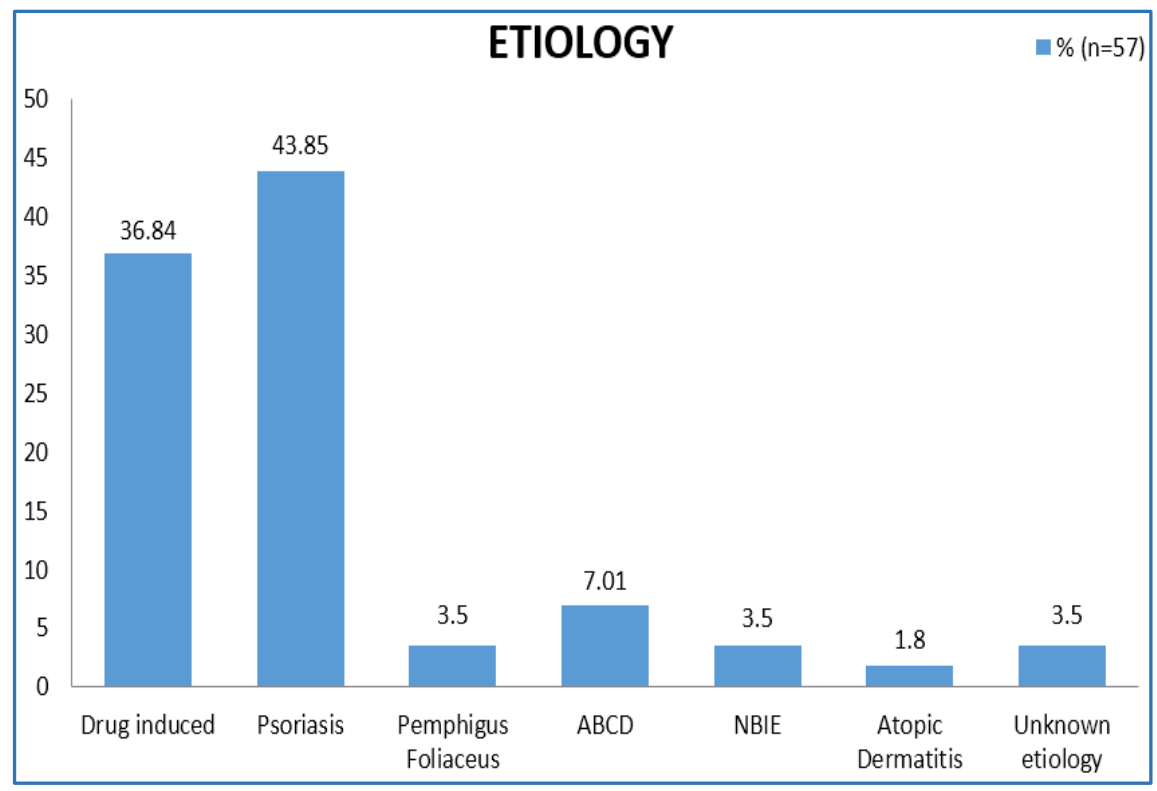

Chart 1.1: Showing the common Etiology

\begin{tabular}{|c|c|}
\hline DRUG & \% (n=57) \\
\hline Indigenous medications & 14.03 \\
\hline $\begin{array}{c}\text { Anticonvulsants } \\
\text { (Carbamazepine, Phenytoin) }\end{array}$ & 12.28 \\
\hline Dapsone & 5.26 \\
\hline ATT & 1.75 \\
\hline Vincristine & 1.75 \\
\hline Unrecordable drug & 1.75 \\
\hline \multicolumn{2}{|c|}{ Table 1.2: Drug induced Erythroderma } \\
\hline
\end{tabular}

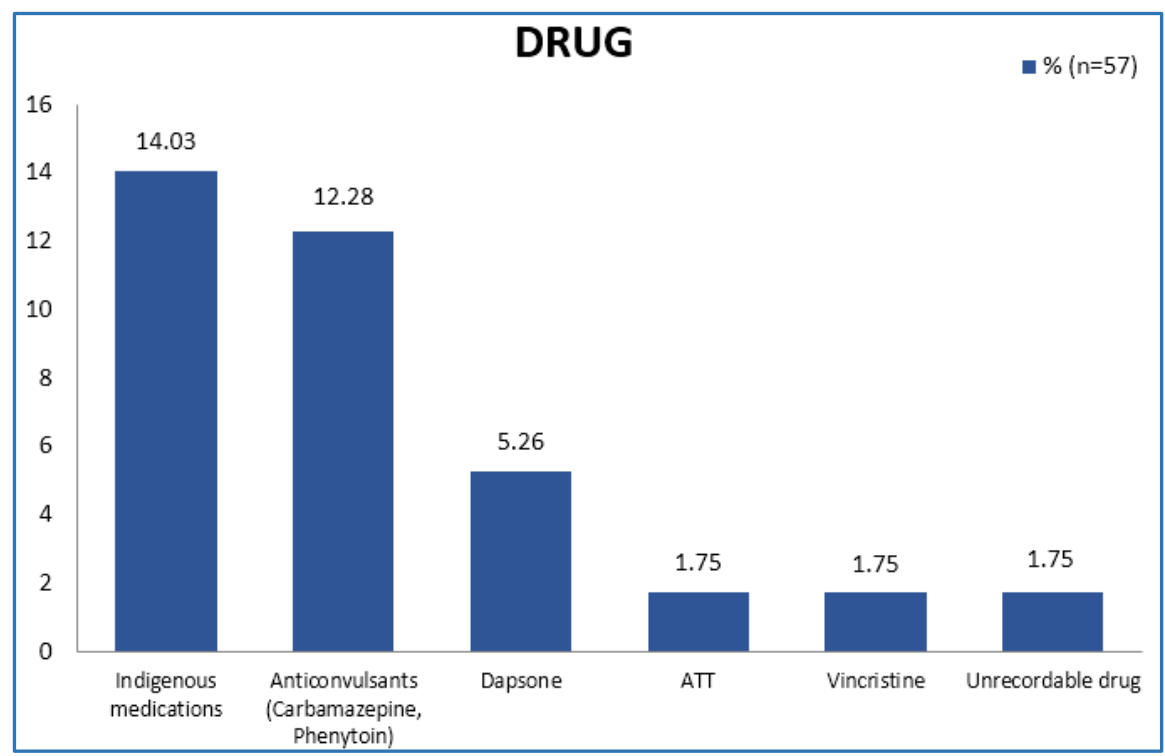

\section{REACTION PATTERNS}




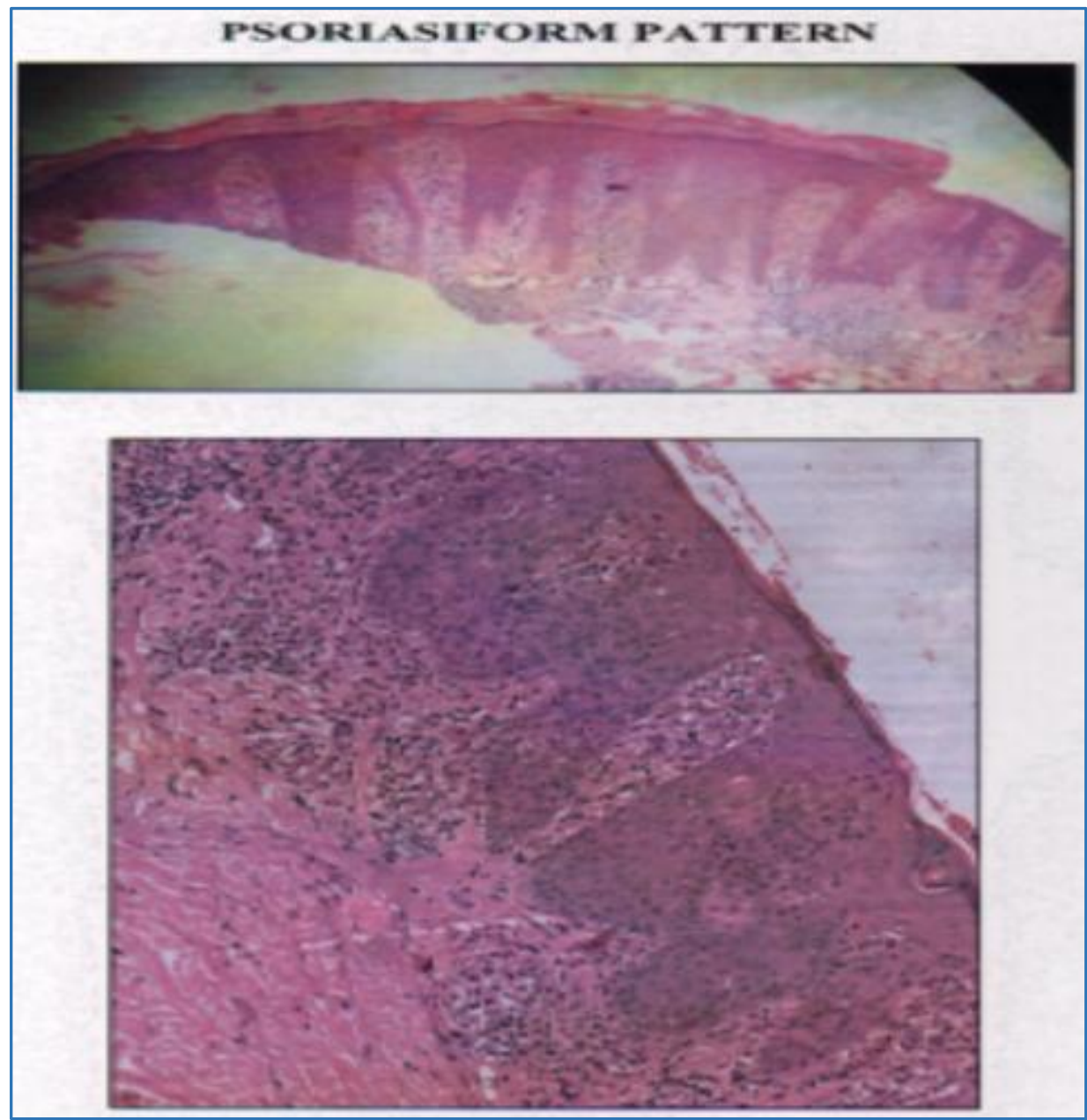

Fig 1.1: Psoriasiform Histopathology-Commonest reaction pattern

\begin{tabular}{|c|c|c|}
\hline Psoriasiform & $\mathbf{3 4}$ & $\mathbf{7 0 . 8}$ \\
\hline Lichenoid & 7 & 14.5 \\
\hline Spongiotic & 6 & 12.5 \\
\hline Vesiculo-bullous & 1 & 2.1 \\
\hline \multicolumn{2}{|c|}{ Table 1.3: Common HPE Patterns } \\
\hline
\end{tabular}

Out of the 57 patients who were recruited in my study, skin biopsies were done in 48 patients. The most common reaction pattern observed was psoriasiform (70.8\%). Other reaction patterns observed are lichenoid (14.5\%), spongiotic (12.5\%), and vesiculo- bullous (2.1\%). (Table 10 and Figure 10).

\begin{tabular}{|c|c|}
\hline NAIL CHANGES & \% (n=57) \\
\hline Pitting & 29.82 \\
\hline Subungual Hyper keratosis & 26.31 \\
\hline Ridges & 43.85 \\
\hline Discolouration & 21.05 \\
\hline Onycholysis & 14.03 \\
\hline Shiny Nails & 52.83 \\
\hline Beau's Lines & 1.75 \\
\hline \multicolumn{2}{|c|}{ Table 1.4: Nail Changes in Erythroderma } \\
\hline
\end{tabular}




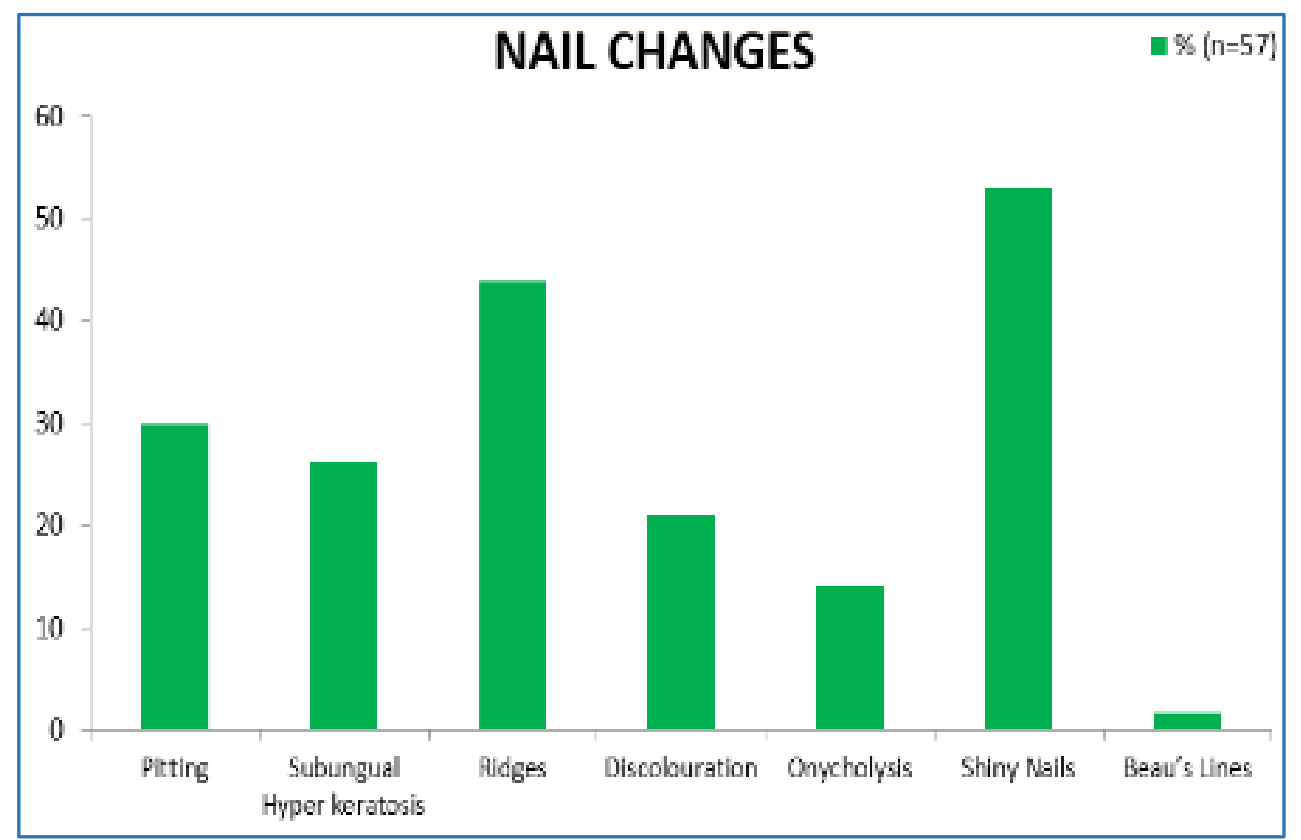

Chart 1.3: Nail Changes in Erythroderma

Nail changes however differed in our study from previous studies. In the study conducted by Sudha R et al: pitting \& onycholysis were the preponderance findings. Hulmani et al demonstrated Ridging as their predominant findings. In our case elongation of nails was the predominant findings.

\begin{tabular}{|c|c|}
\hline SYMPTOMS & $\mathbf{\%}(\mathbf{n}=\mathbf{5 7})$ \\
\hline Exfoliation & 100 \\
\hline Itching & 100 \\
\hline Redness & 96.49 \\
\hline Fever & 80.7 \\
\hline Fever with chills & 35.08 \\
\hline Fluid filled lesions & 5.26 \\
\hline Atopy & 5.26 \\
\hline Contact & 7.01 \\
\hline Swelling of feet & 56.14 \\
\hline \multicolumn{2}{|c|}{ Table 1.5: Symptoms in Erythroderma } \\
\hline \multicolumn{2}{|c}{} \\
\hline
\end{tabular}

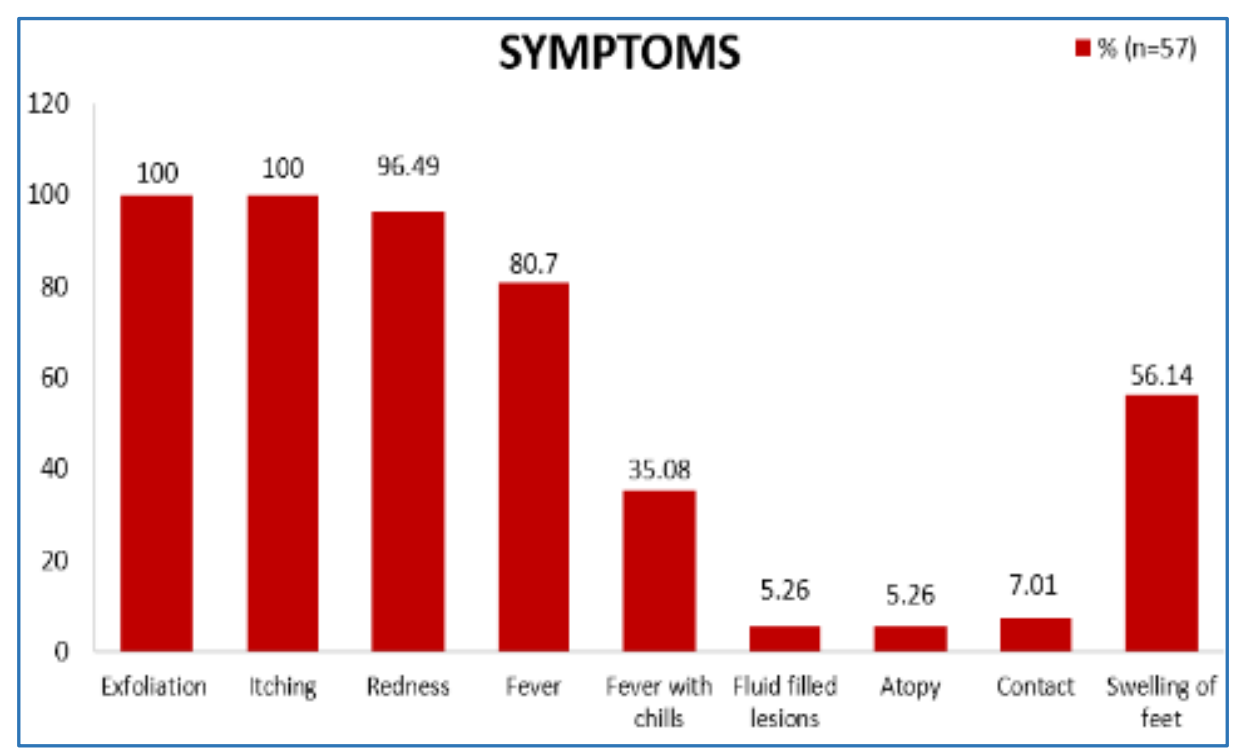

Chart 1.4: Symptoms in Erythroderma

Predominant symptoms-exfoliation of skin 100\%, itching 100\%, redness $96.49 \%$, fever $80.70 \%$, swelling of feet $56.14 \%$, fever with chills $35.8 \%$ contact with allergen $7.1 \%$, fluid filled lesions and atopy $5.26 \%$ 


\begin{tabular}{|c|c|}
\hline COMPLICATIONS & \% (n=57) \\
\hline Anemia & 73.68 \\
\hline Leucocytosis & 57.89 \\
\hline Eosinophillia & 47.36 \\
\hline Elevated ESR & 68.42 \\
\hline Altered RFT & 15.78 \\
\hline Altered LFT & 33.33 \\
\hline Hypoproteinemia & 38.59 \\
\hline Hypoalbuminemia & 40.35 \\
\hline Hepatomegaly (USG) & 7.01 \\
\hline Table 1.6: Complications seen in Erythroderma & \\
\hline
\end{tabular}

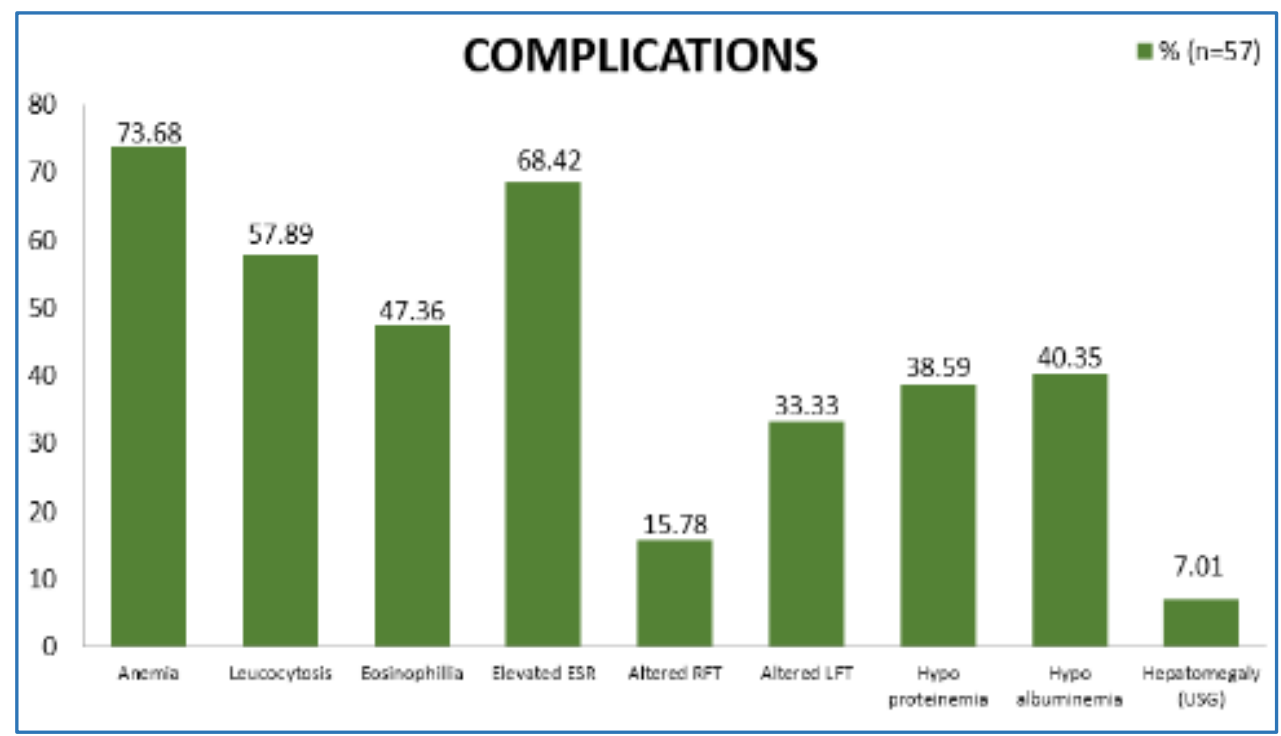

Chart 1.5: Complications seen in Erythroderma

Haemoglobin was low in 42 cases (73.68\%). Leucocytosis was noted in $57.89 \%$ of patients in this study. Eosinophilia was observed in $47.36 \%$ of patients. In this study, ESR was raised in $68.42 \%$ of patients. Hypoproteinemia and hypoalbuminemia occurred in $38.59 \%$ and $40.35 \%$ of cases in this study. Hypoproteinemia with altered albumin to globulin was seen in $63.3 \%$ cases in a study conducted by Manjunath Hulmani et al.[1] and 12\% in Sudha et al.[2] Altered liver function tests was seen in 33.33\% of cases in this study. In a study conducted by Bharatiya PR et al.[3] altered liver function tests was observed in $8.69 \%$ of cases. In this study, altered renal function tests were seen in $15.78 \%$ of cases while in a study conducted by Manjunath Hulmani et al.[1] it was seen in $6.6 \%$ of patients.

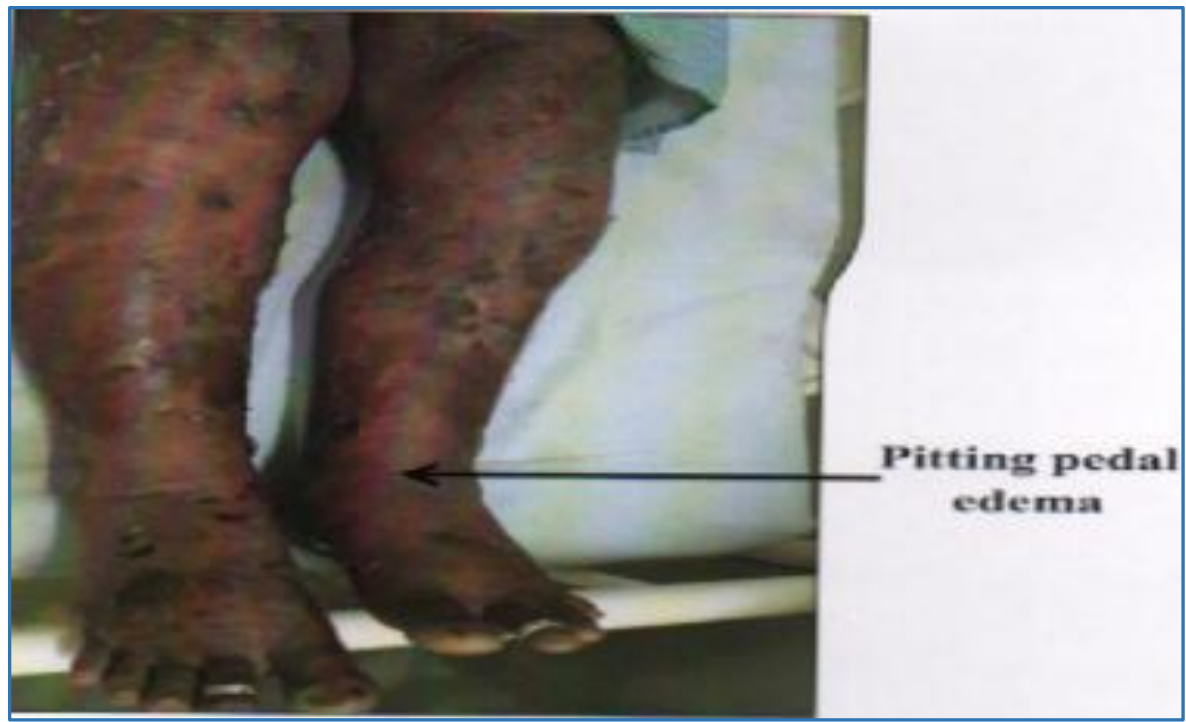

Fig 1.2 : Showing Pitting pedal edema

Systemic features such as Pedal edama was seen in $57.89 \%$ of cases in my study while in a study conducted by Manjunath Hulmani et al $70 \%$ of cases had pedal edema. Lymphadenopathy was seen in 23 cases (40.35\%) in this study, whereas $55.5 \%$ of cases in pal and Haroon et al and 56.66\% cases in Manjunath Hulmani et al one patient had lymphadenopathy. 


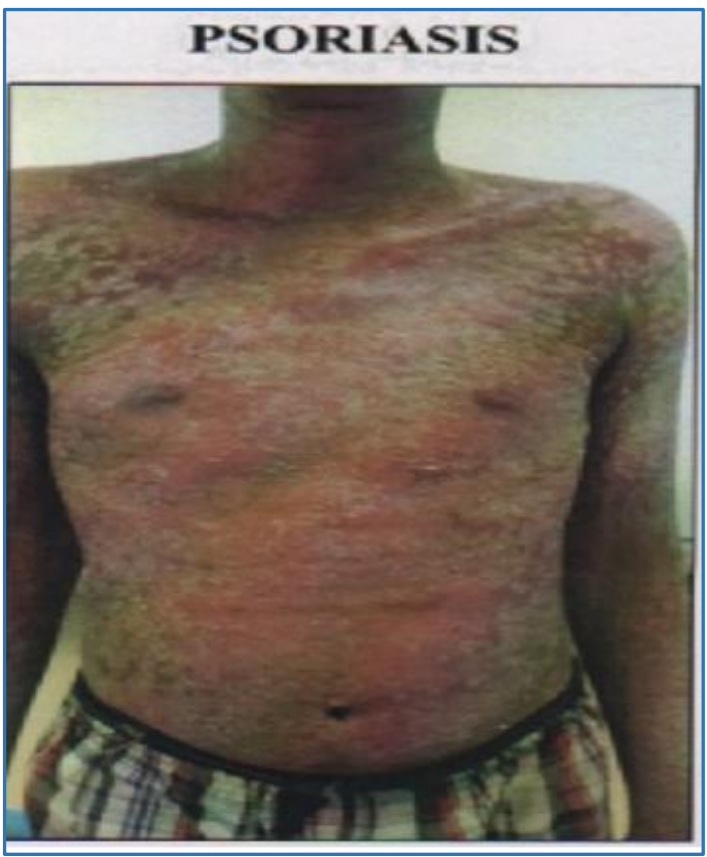

Fig. 1.2 : Erythema \& Exfoliation in a case of Psoriatic Erythroderma 